\title{
Based on the Public Quality Perception Satisfaction Evaluation Theory System Research and Yunnan Province Application Practice
}

\author{
Lei Feng* , Juxiu Huang, Jingxing Liao \\ China National Institute of standardization, Beijing 100191, China
}

\begin{abstract}
Survey on public satisfaction of quality work is one of the effective methods for connecting the quality management department with the public. In this paper, the application of techniques and methods of survey on public satisfaction of quality work is studied and explored from the aspects of the design of survey content index system, data collection, and statistical result analysis based on the survey on public satisfaction of quality work in Yunnan Province, so as to provide enlightenment and reference for the relevant research work in the field of quality.
\end{abstract}

Keywords: Quality work, Satisfaction, Empirical study.

\section{Introduction}

Today, countries of the world attach great importance to the quality construction and take the quality development as an important tool to maintain their international competitive edges. Survey on public satisfaction of quality work is one of the effective ways to connect the quality management department and the public [1]. Evaluation on the public satisfaction of quality work, on the one hand, pays attention to the comparison process and results of public psychology and learns the quality work of government based on the public perceptions of various satisfaction indexes it; on the other hand, can identify the problems in quality work of local government by systematic data analysis, with precise suggestions put forward, thereby promoting the government to improve the quality work and provide the public with better and effective quality work services.

In this paper, the application of techniques and methods of survey on public satisfaction of quality work is studied and explored from the aspects of the design of survey content index system, data collection, and statistical result analysis based on the survey on public satisfaction of quality work in Yunnan Province (2018-2019), so as to provide enlightenment and reference for the relevant research work in the field of quality [2-3].

\section{Research methods}

The evaluation on the public satisfaction of quality work is mainly carried out based on product quality, engineering quality, service quality, environmental quality and quality

* Corresponding author: 1053038950@qqq.com 
awareness. The evaluation index system is built with the public as the core following the evaluation criterion of public perception [4].

\subsection{Design of survey content index system}

The survey on satisfaction of quality work takes product quality, engineering quality, service quality, environmental quality and quality awareness as the first-level indicators [5]. In this survey, the contents easy to be felt and closely related to daily life are selected the evaluation indexes. The satisfaction survey is a process of quantitative analysis, which is mainly used to reflect the attitude of the surveyed on survey contents with figures. In this study, 5 point Likert scales are adopted for measurement; the specific index system and measurement method are shown in Table 1.

Table 1. The indexes of public evaluation on quality work of the government.

\begin{tabular}{|c|c|c|}
\hline $\begin{array}{l}\text { First-level } \\
\text { indexes }\end{array}$ & Measurement indexes & $\begin{array}{l}\text { Measurement } \\
\text { methods }\end{array}$ \\
\hline \multirow{5}{*}{$\begin{array}{l}\text { Product } \\
\text { quality }\end{array}$} & Foods and Drugs & \\
\hline & Agricultural products such as grain, vegetables, & \\
\hline & fruits, meat, and aquatic products & \\
\hline & Consumer goods & \\
\hline & Special equipment & \\
\hline \multirow{8}{*}{$\begin{array}{l}\text { Engineering } \\
\text { quality }\end{array}$} & Constructional engineering & \\
\hline & Public transportation engineering & \\
\hline & Short-distance public transport service & \\
\hline & Long-distance transport service & \\
\hline & Communication and network service & Very dissatisfied \\
\hline & Banking service & $\mathrm{i}=1$; \\
\hline & Insurance service & Dissatisfied $\mathrm{i}=2$ \\
\hline & E-commerce service & General $\mathrm{i}=3$; \\
\hline \multirow{9}{*}{$\begin{array}{l}\text { Service } \\
\text { quality }\end{array}$} & Logistics and express service & Satisfied $i=4$ \\
\hline & Primary and secondary education service & Very satisfied $i=5$ \\
\hline & Medical service & \\
\hline & Pension service & \\
\hline & Public service & \\
\hline & Tourism service & \\
\hline & Public cultural and sports services & \\
\hline & Home renovation service & \\
\hline & Water quality of rivers and lakes & \\
\hline
\end{tabular}




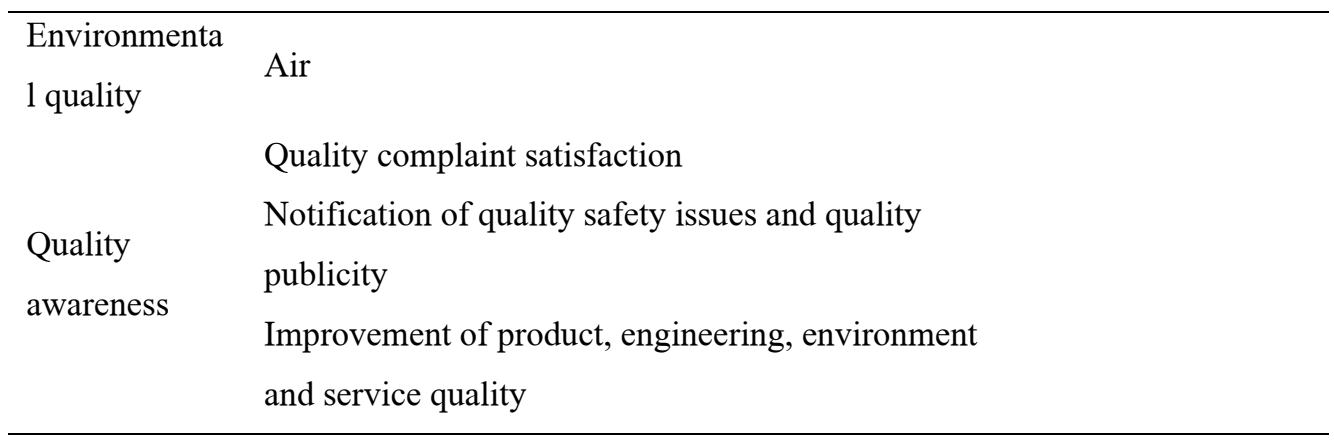

\subsection{Data collection}

The survey adopts the stratified sampling method, which collects data through online survey combined with offline interception visits. This survey recovers 3,700 effective samples of public satisfaction of quality work of Yunnan Province.

\subsection{Evaluation method}

The satisfaction indexes can reflect the overall feeling and evaluation of the surveyed on a certain industry. The higher average score means the higher satisfaction of the surveyed, and vice versa. The computational formula is shown below:

$$
\begin{gathered}
\mathrm{Q}=\frac{\sum_{i=1}^{r} m_{i} q_{i}}{\sum_{i=1}^{r} q_{i}}(\mathrm{r}=5,4,3,2 、 1) \\
\mathrm{S}=\sum_{k=1}^{l} \beta_{k} \sum_{j=1}^{k} \alpha_{j} \cdot Q
\end{gathered}
$$

Where, S refers to the total score of government quality work satisfaction; Q refers to the score of satisfaction of a certain measurement index; mi refers to the valuation of satisfaction measurement option of index $\mathrm{i}(\mathrm{m} 1=20, \mathrm{~m} 2=60, \mathrm{~m} 3=60, \mathrm{~m} 4=80, \mathrm{~m} 5=100)$; $a \mathrm{j}$ refers to the weight of measurement index $\mathrm{j}$; and $\beta \mathrm{k}$ refers to the weight of the first-level index $\mathrm{k}$. The weight of each index is determined according to the historical survey data and Delphi method.

\section{Analysis on applications in Yunnan province}

\subsection{Statistical results}

As shown by the survey results, the comprehensive score of the survey on satisfaction of quality work in Yunnan Province is 69.36, which means that the residents are fairly satisfied with the quality work [6]. As for the first-level indexes, environmental quality is outstanding, with a score of 71.52; followed by engineering quality (70.20), service quality (68.96) and quality awareness (68.15); and product quality has a lower score (67.96), as shown in Fig. 1. 


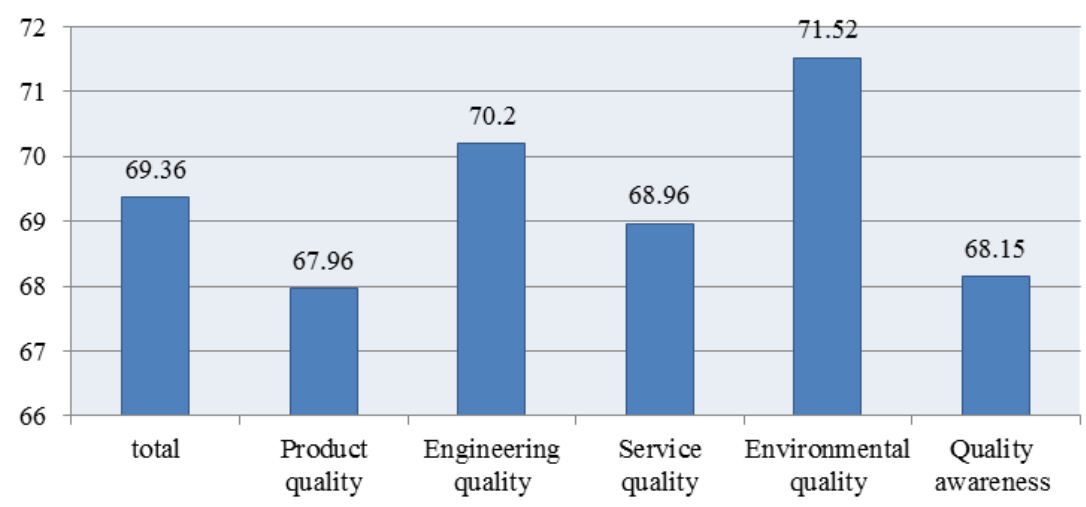

Fig. 1. Overall situation of public satisfaction of quality work in Yunnan Province.

The results of evaluation on product quality, engineering quality, service quality, environmental quality and quality awareness are shown in Fig. 2. 


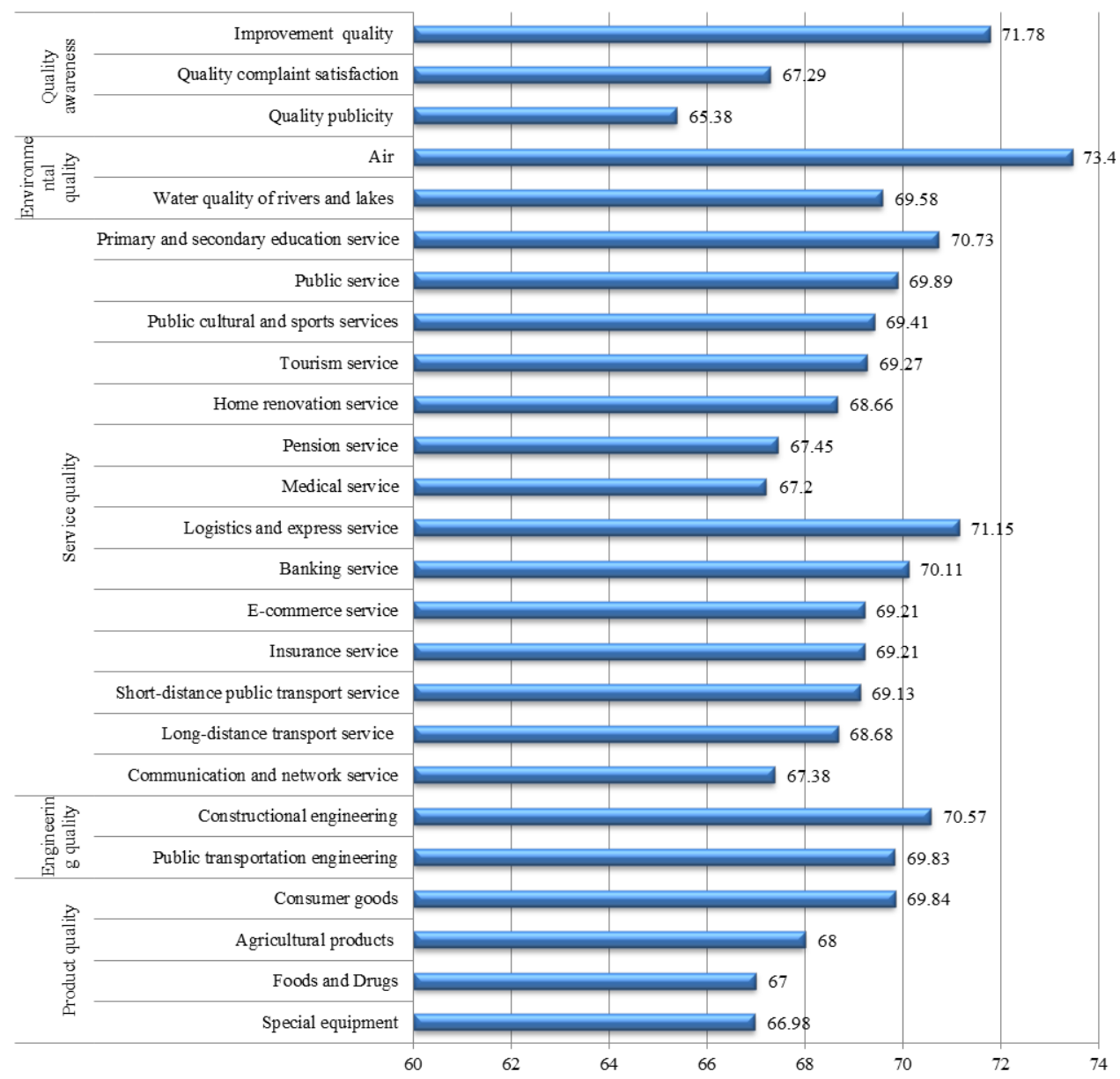

Fig. 2. Results of evaluation on public satisfaction of quality work in Yunnan Province.

\subsection{Analysis of influence factors}

The essence of quality work satisfaction is the function of difference between the quality effect that can be perceived by the public and the expectation of quality [7]. Therefore, the in-depth understanding of characteristics of the population involved in satisfaction evaluation will provide support for the government to make decisions, and improve the public satisfaction of quality work. Considering that the public expectation may be affected by multiple factors, such as social background, perception, individual demand, previous experience and living area environment, the survey on the satisfaction of quality work shall also be carried out in combination with the above-mentioned variables.

\subsubsection{Analysis on the surveyed at different ages}

The results show that the score of satisfaction increases with the increase of age of the surveyed. In specific, the ones after 60s (50-59 years old) have the highest satisfaction of government quality work, with the score of 71.19 ; followed by the ones after 80 s $(30-39$ years old), the ones after 50s (above 60 years old), and the ones after 70s (40-49 years old), 
with the scores of 70.86, 70.74, and 68.97, respectively; and the ones after 90s (18-29 years old) have the relatively low satisfaction, with the score of 67.23, as shown in Fig. 3.

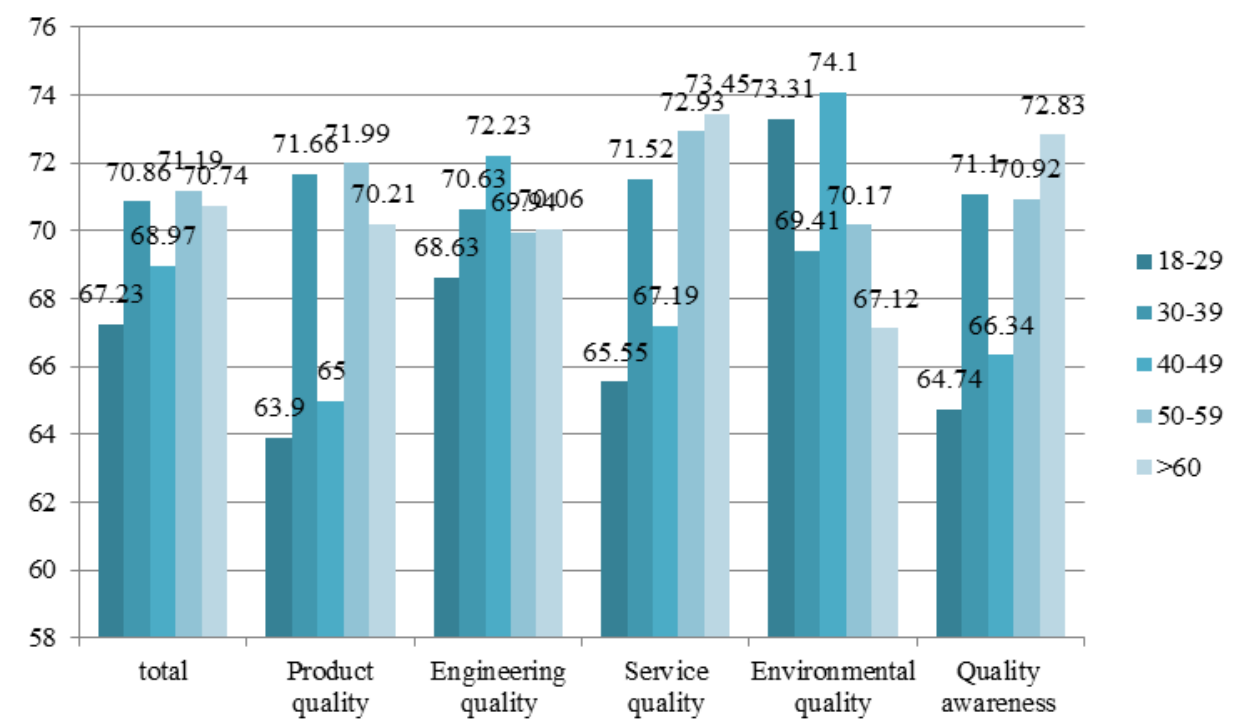

Fig. 3. The satisfaction of government quality work of residents at different ages.

\subsubsection{Analysis on the surveyed of different genders}

The results show that there is only a small difference in the satisfaction scores of each index between genders; in specific, the scores given by the male are slightly higher than those given by the female. In general, the satisfaction score of the male is 69.71 and that of the female is 69.03. Therefore, the male residents have a higher satisfaction score of quality work of Yunnan Province than the female residents, as shown in Fig. 4.

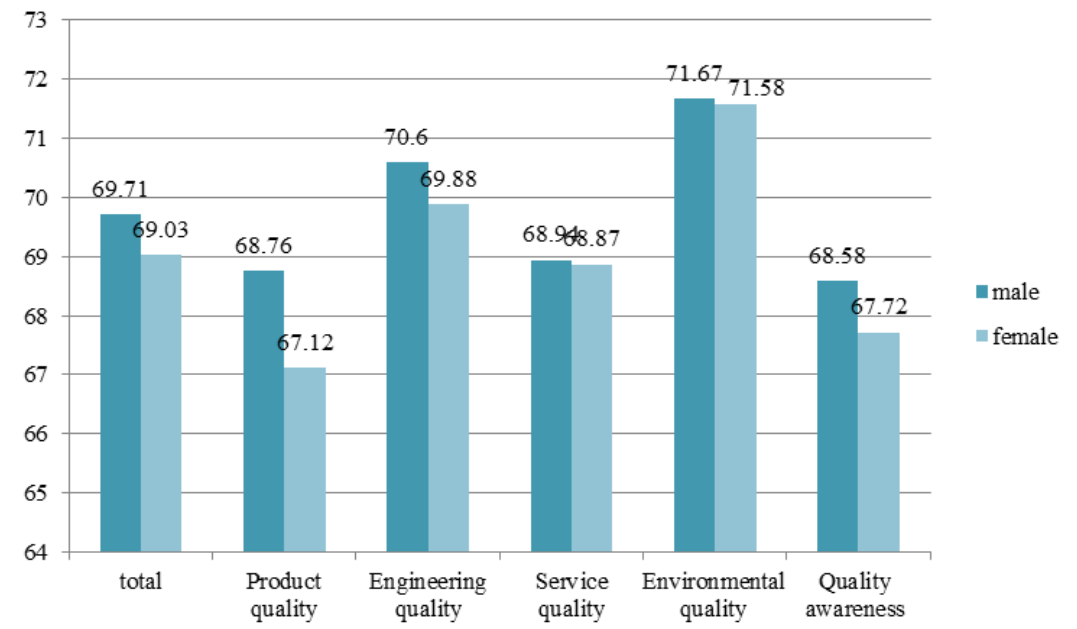

Fig. 4. The satisfaction of government quality work of residents of different genders. 


\subsection{Analysis on the surveyed with different levels of education}

The results show that the score of satisfaction increases with the increase of academic qualifications. The scores of satisfaction are respectively $68.65,69.39,69.45$, and 69.72 in the population at primary school level and below, population at senior high school/ technical secondary school/technical school level, population at junior high school level, and population at the undergraduate level. The residents at the junior college level have the highest satisfaction of government quality work, with the score of 69.77 . The scores of satisfaction of population with different academic qualifications are shown in Fig. 5.

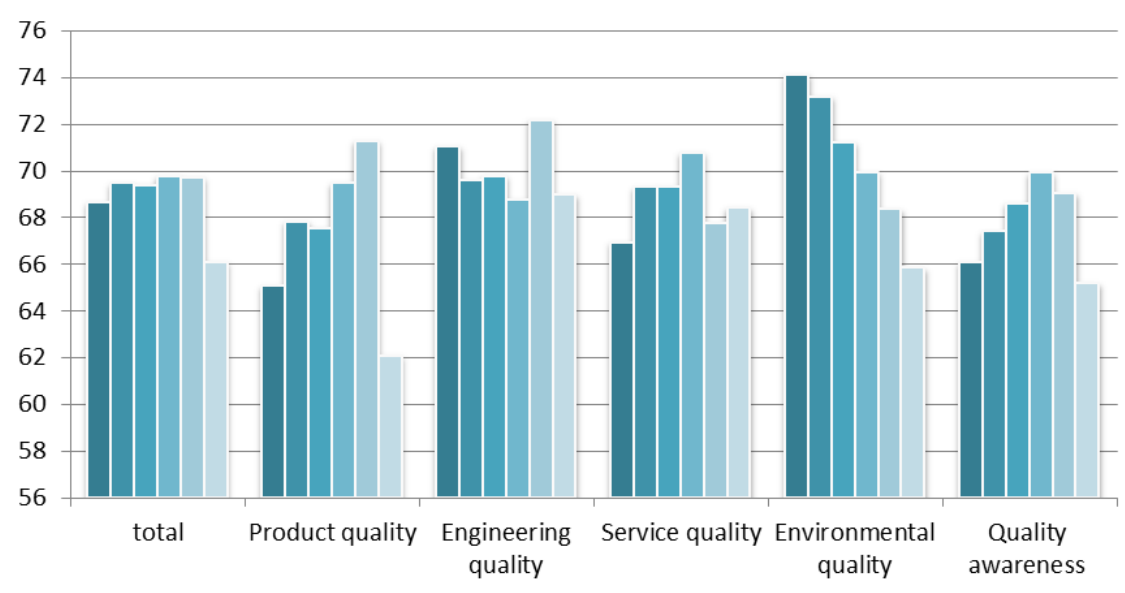

Fig. 5. The satisfaction of government quality work of residents with different levels of education.

\section{Conclusion}

Based on the empirical study on public satisfaction of government quality work, we have built a quality work satisfaction survey index system. Through collecting the data of survey on the satisfaction of quality work of Yunnan Provincial Government and combining with the statistical findings, we hereby propose the following suggestions for Yunnan Provincial Government to carry out quality improvement actions, strengthen the overall quality supervision, comprehensively improve the quality level, and promote the implementation of provincial construction based on quality:

\subsection{Precisely improve quality services aiming at quality shortcomings}

The government shall, based on the results of evaluation on the public quality satisfaction survey report, attach importance to quality shortcomings, carry out quality work in a purposeful and focused manner, and improve the satisfaction of the public on quality work. The government shall also improve the complaint handling mechanism, implement an accountability and time-limited response system, and assign a receiver for specific complaint information; the receiver shall be responsible for handling the complaint, and provide result 
feedback within the specified time, so as to ensure that each complaint can receive a response, thus improving the satisfaction of handling of quality complaints [8].

\subsection{Strengthen quality publicity, and help the quality to improve steadily}

In order to steadily increase the quality and promote the quality satisfaction of the public, it is suggested that the local governments shall conscientiously implement the decisions and arrangements of the Party Central Committee and the State Council, to improve the development quality and efficiency, and carry out the quality improvement actions focused on the strategy of developing cities (counties) based on quality [9]. At the same time, local governments shall actively carry out all-round publicity and education activities in various forms and contents, innovate in publicity forms of quality work, carry out publicity and education by multiple channels and methods, and cultivate quality awareness and create quality atmosphere in the society. They shall also give full play to the role of news media as the main channel of quality publicity, and adhere to the correct direction of public opinions $[10]$.

\subsection{Strengthen quality supervision and promote quality brand building}

It is suggested that the local governments shall establish the strong awareness of quality first, carry out quality improvement actions, and vigorously promote standardized production of foods, brand creation, quality and safety supervision; implement the access mechanism of foods and drugs, effectively improve the quality of foods, drugs and agricultural products, continuously improve the product quality, and improve the public satisfaction of product quality. The local governments shall also, based on the national "Internet +" action plan, strengthen the information construction of quality inspection, and gradually release the energy of "Internet + Quality Inspection"; strengthen the effective connection between risk monitoring and random checking; establish a quality safety inspection linkage working mechanism; and precisely, effectively and severely crack down on quality violations, to effectively improve the quality level.

\section{Acknowledgements}

This research was financially supported by the government quality monitoring and evaluation system improvement and implementation project (582019C-7110).

\section{References}

1. M L Morris, R Tripp, and A A Dankyi. Adoption and Impacts of Improved Maize Production Technology: A Case Study of the Ghana Grains Development Project, International Maize and Wheat Improvement Center (CIMMYT), (1999)

2. J O Ouma, F M Murithi, W M wang, H Verkuijl, M Gethi and H D Groote. Adoption of Maize Seed and Fertilizer Technologies in Embu District, International Maize and Wheat Improvement Center (CIMMYT), (2002)

3. F H Zheng, Red Data Book of Evaluation on Performance of Local Governments in China (2012), Xinhua Publishing House, 185, (2012)

4. D L Wang, X Z Song, Survey and Empirical Study on Public Service Satisfaction Taking the Survey on Public Industry in Jinan City as an Example [J]. Chinese Public Administration, 6, (2009) 
5. G Casella, R L Berger. Statistical Inference (2nd ed.) [M]. Pacific Grove: Duxbury Press, (2002)

6. D Freedman. Statistical Models: Theory and Practice (revised ed.) [M]. New York: Cambridge University Press, (2009)

7. Q J Shi. Government Performance Evaluation: Concepts, Methods and Applications of Evaluation Results [M]. Beijing: Peking University Press, (2016)

8. P Jin. Study on the "High Quality Development" Economics [J]. China Industrial Economics, 4, 5-18, (2018)

9. C Z Yang, F Yang. Analysis of Housing Changes in Contemporary Tibetan FamiliesBased on Census Data [J]. China Tibetology (Beijing), 4, 103-114, (2018)

10. S Z Zheng, X Zhao. Who can promote the development of high quality: the government or the efficient market? - Empirical Test Based on Panel Threshold Model [J]. Contemporary Economic Management, 42, (2020) 